\title{
Raynaud's Phenomenon: A Brief Review of the Underlying Mechanisms
}

\author{
Manal M. Fardoun ${ }^{1 \dagger}$, Joseph Nassif ${ }^{2 \dagger}$, Khodr Issa ${ }^{3}$, Elias Baydoun ${ }^{1 *}$ and Ali H. Eid ${ }^{*}$ \\ ${ }^{1}$ Department of Biology, Faculty of Arts and Sciences, American University of Beirut, Beirut, Lebanon, ${ }^{2}$ Department of \\ Obstetrics and Gynecology, Faculty of Medicine, American University of Beirut, Beirut, Lebanon, ${ }^{3}$ Department of \\ Pharmacology and Toxicology, Faculty of Medicine, American University of Beirut, Beirut, Lebanon
}

OPEN ACCESS

Edited by:

Paul H. Ratz,

Virginia Commonwealth University,

USA

Reviewed by:

Chris R. Triggle,

Weill Cornell Medical College in Qatar,

Qatar

Robert B. Moreland Astellas Pharma Global Development,

Thomas J. Eddinger, Marquette University, USA

*Correspondence:

Ali H. Eid

ae81@aub.edu.Ib

Elias Baydoun

eliasbay1@aub.edu.Ib

tThese authors have contributed equally to this work.

Specialty section:

This article was submitted to Cardiovascular and Smooth Muscle

Pharmacology,

a section of the journal

Frontiers in Pharmacology

Received: 25 August 2016 Accepted: 03 November 2016 Published: 16 November 2016

Citation:

Fardoun MM, Nassif J, Issa K, Baydoun E and Eid AH (2016)

Raynaud's Phenomenon: A Brief

Review of the Underlying

Mechanisms.

Front. Pharmacol. 7:438

doi: 10.3389/fphar.2016.00438
Raynaud's phenomenon (RP) is characterized by exaggerated cold-induced vasoconstriction. This augmented vasoconstriction occurs by virtue of a reflex response to cooling via the sympathetic nervous system as well as by local activation of $\alpha_{2 C}$ adrenoceptors $\left(\alpha_{2 C}-A R\right)$. In a cold-initiated, mitochondrion-mediated mechanism involving reactive oxygen species and the Rho/ROCK pathway, cytoskeletal rearrangement in vascular smooth muscle cells orchestrates the translocation of $\alpha_{2 C^{-}}$ AR to the cell membrane, where this receptor readily interacts with its ligand. Different parameters are involved in this spatial and functional rescue of $\alpha_{2 C}-A R$. Of notable relevance is the female hormone, $17 \beta$-estradiol, or estrogen. This is consistent with the high prevalence of RP in premenopausal women compared to age-matched males. In addition to dissecting the role of these various players, the contribution of pollution as well as genetic background to the onset and prevalence of RP are also discussed. Different therapeutic approaches employed as treatment modalities for this disease are also highlighted and analyzed. The lack of an appropriate animal model for RP mandates that more efforts be undertaken in order to better understand and eventually treat this disease. Although several lines of treatment are utilized, it is important to note that precaution is often effective in reducing severity or frequency of RP attacks.

Keywords: Raynaud's Phenomenon, peripheral vascular disease, alpha 2-adrenergic receptors, estrogen, thermoregulation, Rho kinase

\section{INTRODUCTION}

Cold-induced vasoconstriction of cutaneous arterioles is a normal physiological process that redirects blood from the superficial circulation to internal organs in order to protect the body from excessive heat loss (Charkoudian, 2010). This constriction is mediated by reflex sympathetic release of norepinephrine (Charkoudian, 2010) as well as increased sensitization of the vasculature (Vanhoutte, 1980; Wigley and Flavahan, 2016). When this cold-induced constriction is exaggerated, it leads to a pathological condition known as Raynaud's phenomenon (RP) (Herrick, 2012). This disease can be clinically classified as primary or secondary (Block and Sequeira, 2001). Primary RP is idiopathic, and it is the most common form of the disease (Roustit et al., 2014). On the other hand, Secondary RP could be due to myriad of underlying health conditions such as autoimmune diseases or cancer, as well as lifestyle conditions such as smoking or certain medications 
(Prete et al., 2014). Indeed, 95\% of patients suffering from Scleroderma are diagnosed with RP (Black, 1995).

Raynaud's phenomenon affects up to $10 \%$ of the general population (Garner et al., 2015). Affected individuals suffer from cold-provoked vasospastic attacks (Heidrich, 2010) which are associated with the classic triple-color change (pallor, cyanosis, and erythema) (Maverakis et al., 2014), in addition to puffiness and ulcerations mainly at the level of fingers (Gerbracht et al., 1985). Other distal body organs such as the nose, toes, and nipples are reported to be affected (Block and Sequeira, 2001; Anderson et al., 2004). While there are different manifestations that can be used to diagnose RP, changes in some parameters may also be helpful. For example, serological tests of RP patients show increased levels of endothelin-1 (Zamora et al., 1990), tumor necrosis factor- $\alpha$ (TNF- $\alpha$ ) (Rychlik-Golema et al., 2006), fibrinogen (Spengler et al., 2004), platelet factor (PF-4), and von Willebrand's factor (vWF) (Rychlik-Golema et al., 2006). Magnesium ions and $S$-nitrosothiols levels appear to decrease in $\mathrm{RP}$ patients compared to unaffected individuals (Leppert et al., 1990; Kundu et al., 2014). Furthermore, anti-centromere and anti-centriole antibodies are detected in patients' sera (Gentric et al., 1990; Yamada et al., 2014).

Many hypotheses have been proposed to dissect and explain the underlying mechanisms implicated in the pathogenesis of RP. Recent evidence appears to lend strong support for the mosaic theory of this disease (Greenstein et al., 1996). This theory consolidates the multi-etiology of the disease, involving local, neuronal, and hormonal mediators (Wigley, 2002). Impaired function of any of these mediators may contribute to an exaggerated constriction of cutaneous arteries in response to noradrenaline (Easter and Marshall, 2005). Noradrenaline elicits its effects through binding to adrenergic receptors located on the surface of vascular smooth muscle cells (VSMCs) (Guimaraes and Moura, 2001). Typically, VSMCs have three types of adrenergic receptors (ARs): $\alpha_{1}, \alpha_{2}$, and $\beta_{2}$. Depending on the vascular bed, $\beta_{1}$ and $\beta_{3}$ adrenoceptors may also be present but usually with a lower expression than $\beta 2$ adrenoceptors (Ahles and Engelhardt, 2014). $\beta_{2}$ adrenoceptors are involved solely in vasodilation (McCance and Huether, 2013), whereas $\alpha_{1}$ and $\alpha_{2}$-ARs are responsible for vasoconstriction (Figure 1A). While $\alpha_{1}$-ARs have a wide expression pattern across the vascular tree, $\alpha_{2}$-ARs are predominantly present in smaller blood vessels or arterioles (Polonia et al., 1985). At one point, these receptors were surprisingly found to be present in the protein extract of minced aortas (Chotani et al., 2004). However, histochemical analysis showed that these receptors were expressed in the vasa vasorum of the aorta (Chotani et al., 2004).

Early evidence clearly pointed to the prominent role of $\alpha_{2}$-ARs in local cooling-induced constriction of cutaneous arteries. It is important to note that local cooling causes vasodilation (Johnson and Kellogg, 2010) as well as inhibits $\alpha_{1}$-AR-mediated vasoconstriction (Freedman et al., 1992). Paradoxically, this very cooling also causes vasoconstriction by virtue of its potential to selectively amplify $\alpha_{2}$-AR-mediated constrictive effects (Jeyaraj et al., 2001; Eid et al., 2008). Because they play the key role in the sympathetic constriction of cutaneous vessels, selective potentiation of $\alpha_{2}$-ARs allows their cold-induced constrictive effects to overcome the vasodilatory effects. Accordingly, non-selective $\alpha_{2}$-AR antagonists were, at one point, used to treat peripheral cold-induced vasoconstriction but were not therapeutically effective (Freedman et al., 1993).

Molecular, genetic, and pharmacologic studies show that $\alpha_{2}$-ARs actually comprise three subtypes: $\alpha_{2 A}, \alpha_{2 B}$, and $\alpha_{2 C}$ (MacDonald et al., 1997). These subtypes have their corresponding genes on three different chromosomes, and they are all coupled to inhibitory hetero-trimeric $G$ protein (MacDonald et al., 1997). The search for the particular subtype responsible for $\alpha_{2}$-AR-mediated cold-induced vasoconstriction remained unclear for some time. $\alpha_{2 \mathrm{~A}}$-ARs did not seem to play any role in cold-induced constriction (Chotani et al., 2000). Some reports pointed to the potential use of $\alpha_{2 B}-A R$ antagonists as a treatment option for vasospasms in RP (MacDonald et al., 1997). Much to our surprise, we could not find strong experimental or clinical data that support a role for $\alpha_{2 B}-A R$ antagonists in the treatment of Raynaud's Disease.

Of the $\alpha_{2}$-AR subtypes, $\alpha_{2 C}$-AR was thought to be a vestigial receptor for two main reasons. The first is that $\alpha_{2 \mathrm{C}}$-ARs are sequestered in an intracellular compartment (von Zastrow and Kobilka, 1994), and thus their function was not easily detected by immunohistochemistry assays (MacDonald et al., 1997). The second is that neither the $\alpha_{2 \mathrm{C}}-\mathrm{AR}$ knockout nor the transgenic mice showed major changes; both remained viable, fertile, and almost normal (Sallinen et al., 1997). On the other hand, other evidence emerged to argue against the apparent vestigiality of $\alpha_{2 C}$-AR. First, $\alpha_{2}$-ARs exhibit highly conserved domains present in other adrenoceptors (Nyronen et al., 2001). Second, the apparently normal phenotype may be due to compensation by other $\alpha_{2}$-ARs, and third, $\alpha_{2}$-ARs are differentially expressed in cells of different tissues (MacDonald et al., 1997).

One interesting and rather unique feature of its biology is that upon certain physiologic and pathophysiologic stimuli, $\alpha_{2 \mathrm{C}}-\mathrm{AR}$ can translocate from the endoplasmic reticulum (ER) and Golgi apparatus to the cell membrane. This spatial rescue renders the receptor available for its ligand, whose binding then activates the receptor (Chotani et al., 2000, 2004; Jeyaraj et al., 2001). Upon moderate physiological cooling (i.e., $28^{\circ} \mathrm{C}$ ), $\alpha_{2 \mathrm{C}}-\mathrm{AR}$ is mobilized from the ER/Golgi to the cell surface (Bailey et al., 2004). The now membrane-localized receptors can readily interact with their agonists, become activated and evoke cutaneous vasoconstriction in response to norepinephrine (Jeyaraj et al., 2001). Indeed, it is now evident that the entirety of cold-induced constriction of cutaneous arteries is due to an increased activity of $\alpha_{2 C}$-ARs (Bailey et al., 2004; Eid et al., 2008). As such, $\alpha_{2 C}$-ARs appear to play an important role in the augmented vasoconstriction observed in RP (Bailey et al., 2004).

The mechanism by which $\alpha_{2 \mathrm{C}}-\mathrm{AR}$ translocation takes place involves different players such as reactive oxygen species (ROS), Rho/Rho kinase, and the actin cytoskeleton (Figure 1B). Bailey et al. reported that the Rho/Rho kinase pathway becomes activated as early as few minutes after cells get exposed to cold temperatures (Bailey et al., 2004). The now active Rho evokes the mobilization of $\alpha_{2 C}$-AR to the membrane, and consequently triggers cold-induced vasoconstriction (Bailey et al., 2004). 


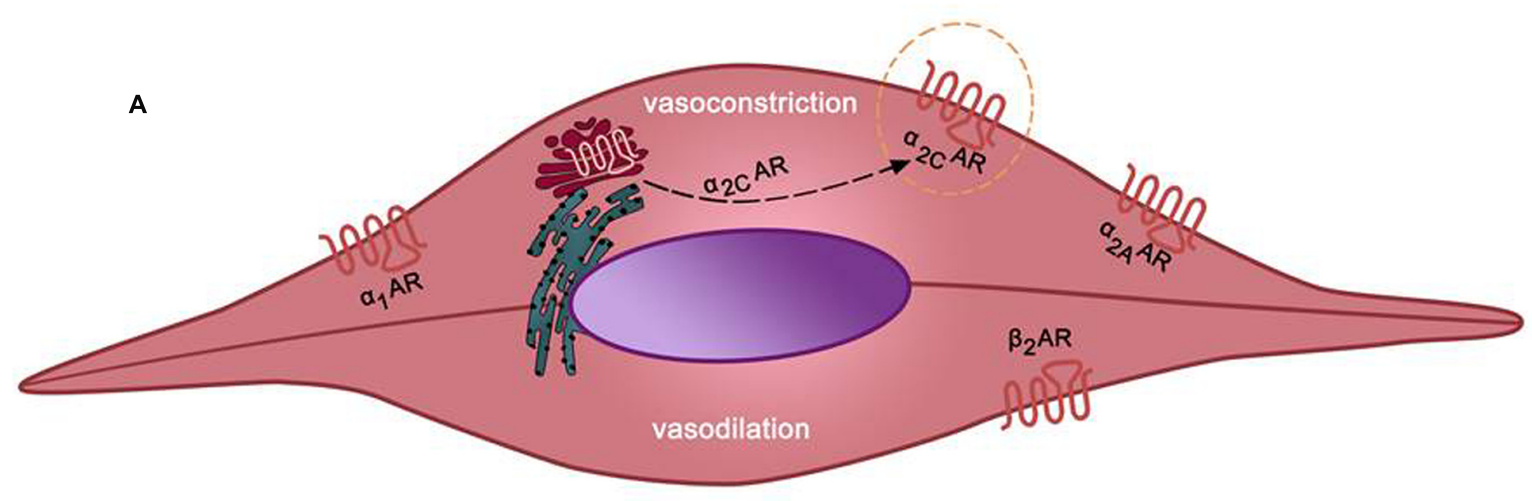

B

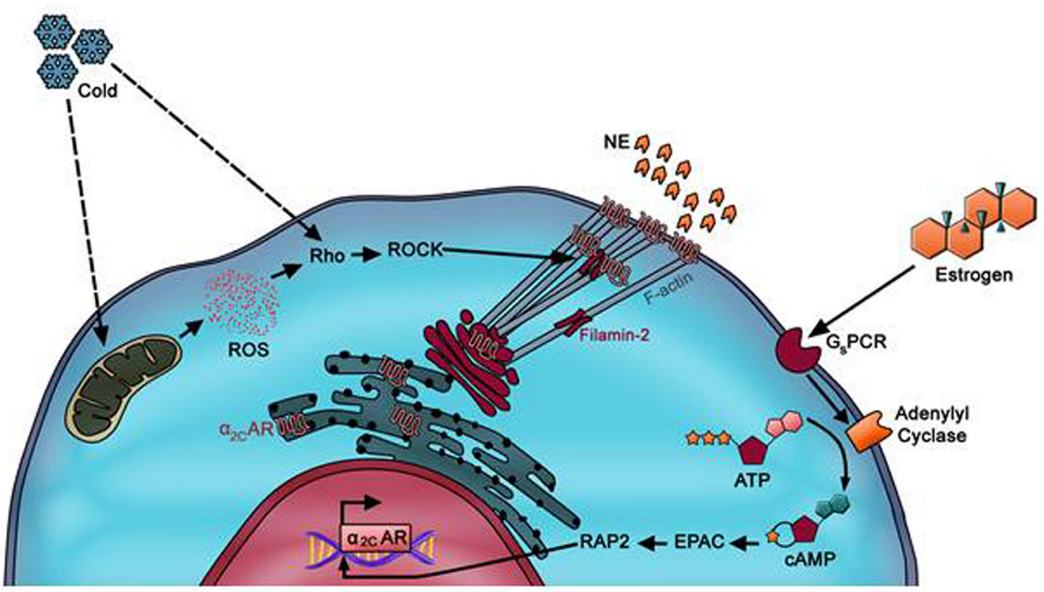

FIGURE 1 | (A) Predominant adrenergic receptors in arteriolar vascular smooth muscle cells (VSMC). $\beta 2 A R$ mediates mediates vasodilation of small microvessels. Vasoconstriction of these vessels occurs via $\alpha 1-\mathrm{AR}, \alpha_{2 A}-\mathrm{AR}$, and $\alpha_{2 C}$-AR. Whereas $\alpha 1-, \alpha_{2 A^{-}}$, and $\beta_{2}$-ARs in these cells are localized at the cell surface, $\alpha_{2 C}-\mathrm{AR}$ (in dotted orange circle) is uniquely trapped intracellularly (mostly trans-Golgi). However, it can be mobilized to the membrane by various stimuli such as cold temperatures. $\alpha_{2 C}$-AR mediates cold-induced vasoconstriction, which when exacerbated may lead to Raynaud's phenomenon (RP). (B) Mechanism of cold-induced mobilization of $\alpha_{2} \mathrm{C}-\mathrm{AR}$. In cutaneous arteriolar SMCs, a decrease in temperature is sensed by the mitochondria, which then releases reactive oxygen species (ROS). ROS, in turn, activates the Rho/ROCK pathway. Subsequent cytoskeletal rearrangements involving F-actin and filamin-2 promote mobilization of $\alpha_{2 C}-A R$ from the endoplasmic reticulum/Golgi to the cell surface.

In this sense, it seems that Rho, rather than $\alpha_{2 C}-A R$, is the "thermosensor" (Bailey et al., 2004). However, additional and rather elegant investigations from the Flavahan group further showed that the mitochondrion is the "thermo-sensitive" organelle in VSMCs (Bailey et al., 2005). Indeed, upon cold stress, it is the mitochondria that initiate the process by releasing ROS, which in turn triggers a redox signal that activates the Rho/Rho kinase pathway leading to spatial redistribution and functional activation of $\alpha_{2 C}$-ARs (Bailey et al., 2005). This cooling-induced Rho activation may then act through calcium sensitization or via modulation of cytoskeletal architecture (Hall, 1998; Jeyaraj et al., 2001; Chitaley and Webb, 2002).

\section{RP AND THE ACTIN CYTOSKELETON}

The cytoskeleton plays a major role in fundamental cellular processes like cell division, migration, cell-cell communication, and protein trafficking (Fletcher and Mullins, 2010). The translocation of $\alpha_{2 C}-A R s$, a main player in $\mathrm{RP}$, from the ER/Golgi to the cell membrane of VSMCs is critical for their activation. This translocation involves many cytoskeletal components such as F-actin and actin/myosin filaments. It is through modulation of the actomyosin filaments that VSMC contraction and ultimately vasoconstriction occur.

Cold-induced, Rho-mediated architectural change occurs by virtue of a rearrangement of the actin superstructure evident by an increase in F-actin, a downstream effector of Rho kinase signaling (Jeyaraj et al., 2012). Interestingly, immunocytochemical analysis shows that intracellular $\alpha_{2 \mathrm{C}}-\mathrm{AR}$ and F-actin are sometimes found to be co-localized in nonvascular cells (Hurt et al., 2000). In a rather elegant and orchestrated series of events, $\alpha_{2 C}$-ARs then get in close proximity and associate with actin filaments, readying themselves for the trafficking process (Jeyaraj et al., 2012). This intimate association 


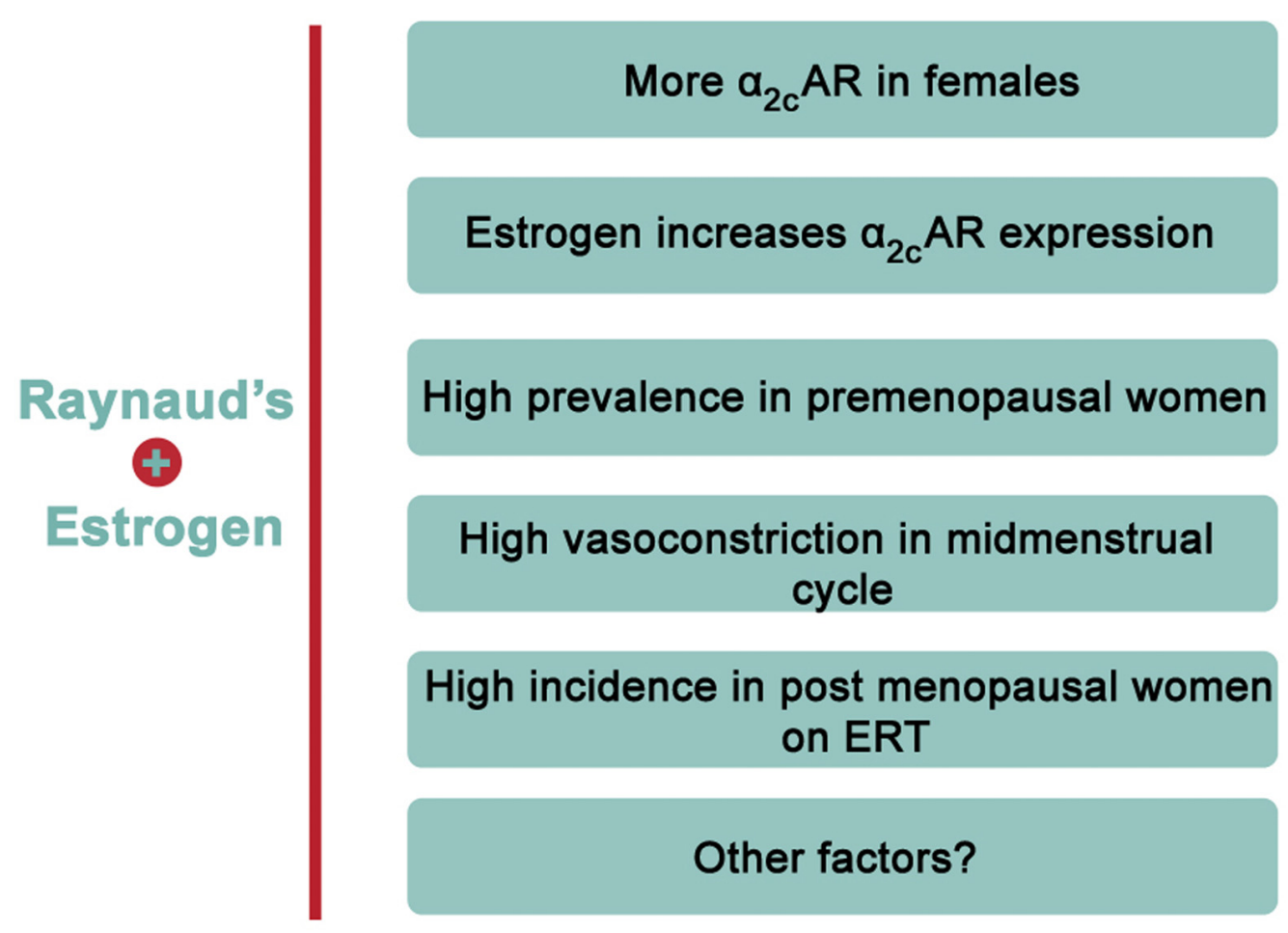

FIGURE 2 | Evidence of positive association between estrogen and RP. Accumulating evidence points to an overwhelming association between estrogen and RP. For instance, estrogen increases $\alpha_{2 C}$-AR but not $\alpha_{2 A}$-AR in human arteriolar smooth muscle cells. Moreover, females have higher expression of $\alpha_{2 C}-A R$ than males. Epidemiologically, RP is reported to have remarkably high incidence in premenopausal females or post-menopausal females on estrogen replacement therapy (ERT).

appears to be mediated by a direct interaction between $\alpha_{2 C^{-}}$ ARs and filamin-2, a cross-linker of actin filaments (Motawea et al., 2013). Indeed, further in silico protein-protein docking examinations confirmed that the interaction between $\alpha_{2 \mathrm{C}} \mathrm{AR}$ and F-actin occurs via the direct binding of $\alpha_{2 \mathrm{C}}-\mathrm{AR}$ to filamin, the actin binding protein (Pawlowski et al., 2014). Interestingly, this interaction has evolved only in warm blooded animals (Pawlowski et al., 2014). Therefore, elucidation of similar proteinprotein interactions can help establish more efficient therapies for exaggerated vasoconstriction. One scenario would include approaches that seek to disrupt the interaction between $\alpha_{2 \mathrm{C}}$-AR and the cytoskeletal component, F-actin.

\section{RP AND ESTROGEN}

Evidence from epidemiological studies reveals a rather interesting finding regarding the prevalence of RP. There is a significantly higher incidence of this disease in females versus age-matched males (Maricq et al., 1993; Garner et al., 2015). Indeed, 70\% of all American patients suffering from RP are females (Maricq et al., 1993). Among patients affected with RP, the ratio of premenopausal females compared to age-matched males is close to 9:1 (Belch and Ho, 2001). This clearly illustrates a gender-based element in the prevalence of the disease, and thus hints to a potential role of sex hormones in its onset or pathology (Maricq et al., 1993). Although it is reported that cardiovascular diseases in general are more prevalent in men and post-menopausal women (Reslan and Khalil, 2012), being a female is among the risk factors of RP (Garner et al., 2015). This conclusion is partly based on a metaanalysis study asserting the much higher prevalence in females compared to males (Garner et al., 2015). In particular, the incidence is higher in premenopausal versus post-menopausal women, with an interesting association between the menstrual cycle and cold-modulated digital blood flow (Greenstein et al., 1996). Further analysis revealed that post-menopausal females receiving unopposed estrogen replacement therapy (ERT) are more likely to suffer from the disease than post-menopausal women that are not receiving ERT (Mayes, 1999). Together, these findings demonstrate that estrogen may explain the higher incidence in premenopausal women (Figure 2). Interestingly, in post-menopausal women receiving opposed estrogen therapy (estrogen and progesterone together), the incidence of RP was not significantly higher than that in premenopausal women (Fraenkel et al., 1998). This may suggest that progesterone negates estrogen's effect in this context, but this remains to be established.

It is worth mentioning that in premenopausal females, noradrenaline-mediated vasoconstriction is higher at the midmenstrual cycle, characterized by relatively high estrogen level, than during the early stage of the cycle (Chan et al., 2001). 


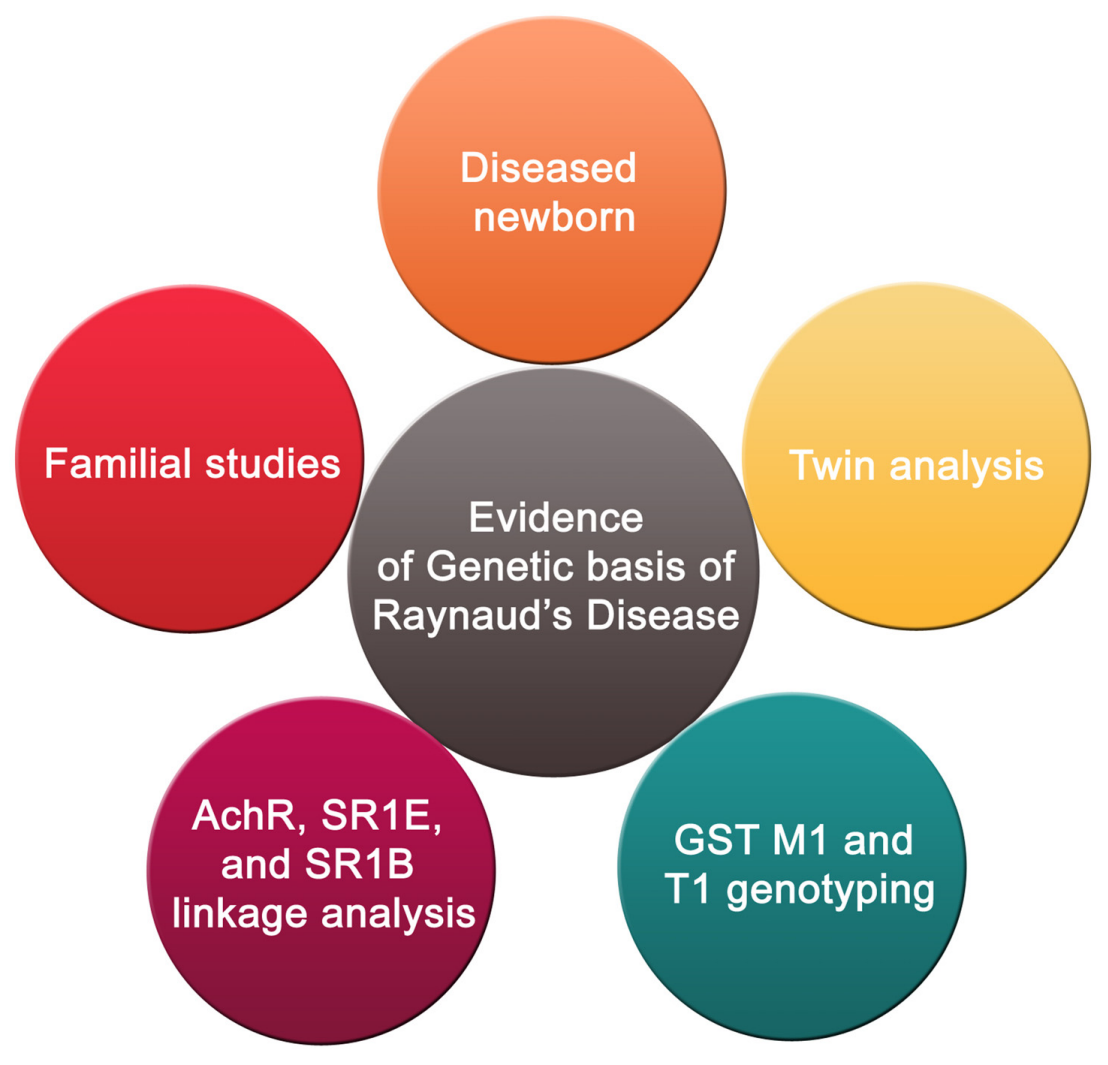

FIGURE 3 | Genetic basis of RP. The genetic basis of RP is supported by familial studies and twin analysis in addition to a reported case of a 1-month male baby diagnosed with the disease. Furthermore, a combination of positive genotypes for both genes encoding glutathione $S$-transferase M1 and T1 subtypes may have a role in susceptibility to RP. Linkage analysis pinpointed five areas corresponding to three candidate genes ( $\beta$-subunit of muscle acetylcholine receptor, $1 \mathrm{E}$ and $1 \mathrm{~B}$ serotonin receptors) which could be associated to RP.

Moreover, human and rat females of reproductive age exhibit higher vascular responsiveness than males (Li et al., 2014). Interestingly, male vascular responsiveness is potentiated when $17 \beta$-estradiol is externally supplemented ( $\mathrm{Li}$ et al., 2014). This implies that estrogen has a direct effect on vasoreactivity, though the mechanisms for such potentiation remain unclear.

The fundamental role of estrogen in regulating body temperature has been defined (Charkoudian and Stachenfeld, 2016). Although estrogen has a vasodilatory effect, it may in many instances decrease body temperature (Charkoudian and Stachenfeld, 2016). Since RP can be considered a vascular thermoregulatory control disorder (Flavahan, 2015), the implication of estrogen in the disease becomes obvious especially in light of the exaggerated response to cold in premenopausal women as well as the higher prevalence of $\mathrm{RP}$ in younger females. This is further supported by the findings of English et al. that there is a gender difference in vasomotor activities in response to estrogen, and that this difference may be a critical contributor to the etiology of vasospastic diseases (English et al., 2001), such as RP.

Evidence indicates that estrogen increases $\alpha_{2 \mathrm{C}}-\mathrm{AR}$ expression in VSMCs and that $\alpha_{2 \mathrm{C}}$-AR-mediates cold-induced vasoconstriction in rat tail arteries (Eid et al., 2007). A notable finding is that among the $\alpha_{2}$-ARs, only the $\alpha_{2 \mathrm{C}}$-AR subtype is differentially expressed in rat tail arteries, with a remarkably greater expression in females (McNeill et al., 1999). We had also reported that in human VSMCs, estrogen does not modulate the expression of $\alpha_{2 \mathrm{~A}}-\mathrm{AR}$ (Eid et al., 2007). The Flavahan group had also established that $\alpha_{2 \mathrm{C}}-\mathrm{AR}$ mediates the entirety of cold-induced vasoconstriction. We then hypothesized and later confirmed that estrogen indeed increases the expression, surface-localization, and function of $\alpha_{2 C}-A R$ (Eid et al., 2007). This estrogen-induced activity of $\alpha_{2 C}-A R$ was followed by a potentiated cold-induced vasoconstrictive response in mouse tail arteries (Eid et al., 2007). Collectively, these pieces of evidence highlight a positive association between estrogen and RP.

\section{RP AND GENETIC BACKGROUND}

As mentioned earlier, RP is either idiopathic, or secondary to another disease like scleroderma. There have been some speculations that genetic predisposition may be a contributor to the onset of this disease (Tan and Arnett, 2000) (Figure 3). However, sequencing results showed no mutations in candidate 
genes that are suspected to play a role in the etiology of the disease (Susol et al., 2000). These candidate genes are the beta subunit of the muscle acetylcholine receptor and the serotonin $1 \mathrm{~B}$ and $1 \mathrm{E}$ receptors (Susol et al., 2000). Nonetheless, others continued to suggest that there is a genetic factor contributing to the prevalence of this disease (Pistorius et al., 2006). This assertion is supported by familial studies and twin analysis (Pistorius et al., 2006). Recently, there was a reported case of a 1 month male baby diagnosed with RP (Sharathkumar and Castillo-Caro, 2011). In light of this case, it was speculated that there could be a genetic basis of the disease. However, much evidence remains lacking before a strong causative link between genetics and RP can be affirmed.

Interestingly, studies of RP patients that were exposed to vinyl chloride monomer (VCM) suggest that the interaction between a certain genetic background and environmental conditions may play a role in increasing the onset of RP in VCM-exposed individuals (Fontana et al., 2006). In 2006, Fontana et al. (2006) investigated whether there is an association between polymorphisms in glutathione $S$-transferase $\mathrm{M} 1$ and $\mathrm{T} 1$ genes and RP patients exposed to VCM (Fontana et al., 2006). The results showed that the combination of positive genotypes for both genes may increase susceptibility to RP (Fontana et al., 2006). In another study, using 298 microsatellite markers, a twostage whole genome screen of six extended families having at least three RP patients in each family was undertaken (Susol et al., 2000). Linkage analysis identified five chromosomal areas of possible linkage. These were mapped to three candidate genes ( $\beta$-subunit of muscle acetylcholine receptor, $1 \mathrm{E}$ and $1 \mathrm{~B}$ serotonin receptors) which could be associated with RP (Susol et al., 2000). This provides evidence of a genetic basis for RP susceptibility. The fact that five possible linkages were highlighted indicates that RP may be an oligogenic rather than monogenic condition. However, more research is needed to ascertain this suggestion, since some of the findings reported may be false positives (Susol et al., 2000). It would, therefore, be interesting to screen in a large pool of RP patients, for mutations or SNPs in these candidate genes.

\section{TOXICOLOGICAL BASIS OF RP}

Many of the heightened vasoreactivity responses observed in $\mathrm{RP}$ are due to either sympathetic or local causes. Stressors such as cold temperatures or emotional anxieties fall under the sympathetic category, since they cause vasoconstriction via noradrenaline. On the other hand, mechanical and chemical stresses fall under the "local" category since they directly affect a body organ that will show symptoms of the disease. A prominent body area that could be affected by these "local" insults would be the digits. Prolonged exposure to vibration at the level of the hand and arm is an example of mechanical stress. Also known as vibration-induced white finger, this hand-arm vibration syndrome is indeed one form of secondary RP that is due to occupational hazards (White et al., 2004). Continuous insults of the hand and arm by vibrating machines can prime these organs for increased vasospastic attacks upon a thermal or emotional stress. With the progression of this condition, such vibration can cause increased digital vasospasm even at room temperature (White et al., 2004). Therefore, it is not surprising that vascular symptoms are highly prevalent among workers whose job requires handling vibrating tools (White et al., 2004).

One of the prominent examples of chemical stressors in $\mathrm{RP}$ is VCM. This monomer is a colorless gas used in the manufacturing of plastic, particularly poly vinyl chloride (PVC). Interestingly, almost one third of workers exposed to PVC suffer from RP (Maricq et al., 1978). Angiography of these patients' hands showed vascular tone changes and vascular lesions such as narrowing of the digital arteries (Falappa et al., 1982). This is not surprising since angiographic and capillaroscopic examinations have shown that exposure to VCM is toxic for the endothelium (Maricq et al., 1976; Falappa et al., 1982). Furthermore, exposure to VCM was shown to significantly contribute to acroosteolysis of distal phalanges of hands, which was recurrently associated with symptoms of RP (Wilson et al., 1967). Indeed, and as mentioned earlier, a higher prevalence of RP among French workers exposed to PVC was reported (Fontana et al., 2006). Taken together, these observations support the notion that a persistent toxic effect of polyvinyl chloride can contribute to the onset and pathogenesis of RP.

There are other chemical compounds or even medicinal drugs that are linked to the onset of RP. Some examples include arsenic, nicotine, and the drug gemcitabine. Indeed, a positive correlation seems to exist between Arsenic and RP. A study in Chile shows that increased prevalence of signs and symptoms of peripheral vascular disease, including RP, are associated with Arsenic-contaminated drinking water (Nordberg et al., 2014). Contextually, Arsenic-exposed smelter workers exhibit heightened vasospastic reactivity in the fingers, reminiscent of RP (Lagerkvist et al., 1986; Hall, 2002; William and Markowitz, 2007). Together, these findings provide some evidence of arsenic being a player in the etiology of RP.

Smoking has been long found to positively associate with RP (Garner et al., 2015). Moreover, nicotine, one main constituent in tobacco, is known to significantly decrease blood flow and increase vascular resistance (Cardelli and Kleinsmith, 1989). It is thus not surprising that nicotine can exacerbate symptoms of RP (Cherniack et al., 2000; Jackson, 2006), so much so that avoiding nicotine has been suggested as one element in the treatment of RP of the nipple (Anderson et al., 2004).

Some drugs such as gemcitabine, a nucleoside analog used in chemotherapy (Carmichael, 1998), could evoke symptoms reminiscent of RP (Yamada et al., 2014). Indeed, when orally administered, it appears to cause pain, swelling, and whitening of the digits, all of which are typical of RP (Carmichael, 1998). Indeed, a case of RP and digital necrosis after receiving gemcitabine for bladder cancer has been reported (D'Alessandro et al., 2003). Furthermore, a scleroderma patient developed digital ischemia after receiving a combined treatment with gemcitabine and carboplatin (Clowse and Wigley, 2003). Interestingly, the association of gemcitabine chemotherapy with digital ischemic events appear to be more common than previously suspected, especially in patients with tobaccoassociated cancers (Kuhar et al., 2010). While the mechanisms 
for this gemcitabine-induced vascular insult remain unclear, it is proposed that endothelial damage as well as thrombotic microangiopathy (Venat-Bouvet et al., 2003; Holstein et al., 2010) may be contributing factors. It is important to note that this gemcitabine-associated vascular toxicity is rather pronounced in scleroderma patients. Similarly, exacerbations of RP symptoms were found to be associated with fluoropyrimidine, namely capecitabine, therapy (Coward et al., 2005). As such, caution should be taken when administering chemotherapeutic agents, especially gemcitabine, to scleroderma or RP patients.

Chemotherapeutic agents, other than gemcitabine, have also been associated with RP. For instance, doxorubicin, and cyclophosphamide-induced scleroderma cases mostly present with diffuse sclerosis and RP (Saif et al., 2016). Moreover, vincristine-induced dose-dependent RP has been reported (Gottschling et al., 2004). Interestingly, a higher prevalence of RP is noted when cisplatin is combined with vinblastine (Vogelzang et al., 1981). Whether the neurotoxic effects of these drugs underpins the increase RP prevalence remains poorly determined. It has been suggested that hyperreactivity in the sympathetic outflow may be an underlying cause (Chant, 1987; Olsen et al., 1987). However, this cannot exclude the possibility that a direct effect on the vasculature of terminal arterioles is also possible, especially that the entirety of cold-induced vasoconstriction is mediated by vascular $\alpha 2 \mathrm{C}-\mathrm{AR}$, independently of any contribution from the endothelial or the sympathetic nervous system (Kristensen, 1979; Eid et al., 2007, 2008; Wigley and Flavahan, 2016).

Epidemiologic data derived from a long-term study involving combined treatment with cisplatin, vinblastine, and bleomycin chemotherapy showed that $35-45 \%$ of these treated patients developed RP (Hansen and Olsen, 1989). Bleomycin, in particular, appears to be the key player in the development of RP in these patients. Indeed, findings of a recent large cross-sectional study showed that the only significant predictor of persistent $\mathrm{RP}$ at follow-up after chemotherapy was the bleomycin dose (Glendenning et al., 2010).

\section{TREATMENT OF RP}

Significant efforts have been undertaken to better understand and treat RP (Lee et al., 2014; Poredos and Poredos, 2016). However, no definitive or specific therapy for this disease has yet been approved by the U.S. Food and Drug Administration (FDA; Landry, 2013). One of the limiting factors in the war against this disease in the incomplete understanding of its pathophysiology (Landry, 2013), which is further compounded by the lack of appropriate animal models for RP. Moreover, a treatment regimen efficacy may depend on the severity and type of the disease, as well as on the degree of vascular damage. Despite that, some medications or treatment options that are thought to alleviate symptoms of the disease are being employed in the clinic. These options can be collectively classified into traditional pharmacological, ethno-pharmacological, nontraditional treatments, and most recently surgical intervention (Table 1).
Traditional pharmacological drugs alleviate RP symptoms by reducing vasoconstriction, inducing vasodilatory effect, or by a yet unclear mechanism. Drugs used for a vasodilatory effect include calcium channel blockers, cyclic guanosine monophosphate (cGMP)-specific phosphodiesterase type-5 (PDE5) inhibitors, prostacyclins, prostaglandin analogs, and alpha-1 blockers. Calciumchannel blockers are the most common and preferred first-line treatment (Halawa, 2001; Thompson and Pope, 2005). However, in the most recent and highly comprehensive Cochrane review where seven randomized trials involving 296 patients were analyzed, it was concluded that oral calcium channel blockers are relatively ineffective in the treatment of primary RP. Authors of this important review conclude that evidence does not support a role of these blockers in reducing the frequency and severity of attacks (Ennis et al., 2016). This is somewhat inconsistent with an earlier metaanalysis which suggested some, albeit small, efficacy of these blockers in reducing the severity of RP attacks (Thompson and Pope, 2005). However, authors of this paper highlighted the notion that most of the trials included in their meta-analysis were crossover studies that did not determine order effect, thus likely introducing some bias (Thompson and Pope, 2005). cGMPspecific PDE5 inhibitors have been used as well (Caglayan et al., 2006). Indeed, in an open-label pilot study involving 40 patients, it was found that digital flow was significantly improved in RP patients receiving the PDE $\mathrm{V}$ inhibitor, vardenafil, treatment (Caglayan et al., 2006). Consistently with this, it was also found that PDE5 inhibitors decrease vasospastic attacks and improve digital blood flow (Lee et al., 2014). Indeed, this efficacy of PDE5 inhibitor was reported in a double-blind, randomized, cross-over study involving 29 patients that were divided into two groups. One group received udenafil, a PDE V inhibitor, and the other a calcium channel blocker, amlodipine, over a period of 4 weeks. Both treatments showed comparable efficacy in RP treatment in regard to decreasing the severity of vasospastic attacks (Lee et al., 2014). In addition, patients receiving the PDE $\mathrm{V}$ inhibitor showed better digital blood flow when compared to those receiving amlodipine (Lee et al., 2014).

Prostanoids are reported to decrease the severity and frequency of vasospastic attacks in RP patients. Their efficacy has been consistently reported in systematic reviews, metaanalyses as well as in multiple randomized clinical trials (Clifford et al., 1980; Mohrland et al., 1985; Wigley et al., 1994; Pope et al., 2000; Scorza et al., 2001; Milio et al., 2006; Kawald et al., 2008). For instance, iloprost, a prostacyclin analog was used to treat 13 patients with RP. In addition to reducing ulcerating lesions, iloprost also caused improvement in blood flow in these patients (Rademaker et al., 1987). Moreover, in a double-blind placebo-controlled trial, it was found that buflomedil causes a reduction in the frequency of attacks, but with no effect on Raynaud severity score (Le Quentrec and Lefebvre, 1991). On the other hand, a Cochrane review concluded that evidence does not support a benefit for beraprost, ketanserin, dazoxiben, and moxisylyte in ameliorating frequency duration or severity of attacks (Stewart and Morling, 2012). However, the authors of this review indicated that the precision of their conclusion is affected by the fact that most of 
TABLE 1 | Various lines of treatment of Raynaud's disease.

\begin{tabular}{|c|c|c|c|}
\hline & Treatment & Effectiveness & Reference \\
\hline \multirow[t]{9}{*}{ Traditional treatment } & Calcium channel blockers & Effective; first-line of treatment & Halawa, 2001; Thompson and Pope, 2005 \\
\hline & PTK inhibitors & Efficient & Furspan et al., 2004, 2005 \\
\hline & PDE5 inhibitors & Inefficient & Lee et al., 2014 \\
\hline & Beta-blockers & Controversial & Marshall et al., 1976Koltringer et al., 1991 \\
\hline & Statins & Emerging/powerful & Abou-Raya et al., 2008 \\
\hline & Prostacyclins & Efficient & Rademaker et al., 1987 \\
\hline & ACE inhibitors & Variable effect & Henness and Wigley, 2007 \\
\hline & Endothelin receptor antagonists & Variable effect & Poredos and Poredos, 2016 \\
\hline & Serotonin receptor antagonists & Effective & Coleiro et al., 2001 \\
\hline \multirow[t]{5}{*}{ Non-Traditional treatment } & Botulinum toxin type $A$ & Efficient & Neumeister et al., 2014 \\
\hline & Chinese herb & Ineffective & Wu et al., 2008 \\
\hline & Ginkgo biloba & Ineffective & Muir et al., 2002 \\
\hline & Acupuncture & Efficient & Appiah et al., 1997 \\
\hline & Laser therapy & Efficient & Hirschl et al., 2004 \\
\hline \multirow[t]{4}{*}{ Surgery } & Thoracic sympathectomy & Effective & Coveliers et al., 2011 \\
\hline & Hand stripping & Effective & Balogh et al., 2002 \\
\hline & Nerve stimulation & effective & Kaada, 1982 \\
\hline & Fat grafting & Encouraging results & Bank et al., 2014 \\
\hline
\end{tabular}

A summary of the traditional and non-traditional therapies, as well as some surgical interventions.

the studies included in their review are poorly designed or executed

Angiotensin receptor blockers, ACE (Angiotensin Converting Enzyme) inhibitors, PTK (protein tyrosine kinase) inhibitors, and endothelin receptor antagonists (ETRAs) are also employed in the treatment of $\mathrm{RP}$ owing to their ability to reduce vasoconstriction. A clinical trial reported that losartan $(50 \mathrm{mg})$ causes a significant reduction in the severity and frequency of spastic episodes (Dziadzio et al., 1999). The therapeutic benefit of using ACE inhibitors in the management of RP seems to be variable (Henness and Wigley, 2007). Some studies have reported that they may have minor benefits, albeit to a lesser extent than traditional therapies (Wood and Ernst, 2006). Indeed, it is not recommended that angiotensin receptor blockers be replaces with ACE inhibitors for the treatment of RP (Linnemann and Erbe, 2016). It is important to note here that although enalapril and captopril are reported to reduce the number of attacks in primary $\mathrm{RP}$, they do not appear to be effective in reducing these attacks in secondary RP (Tosi et al., 1987; Janini et al., 1988). Moreover, in a multicenter, randomized, double-blind, placebo-controlled trial involving 210 patients, quinapril treatment for up to 3 years did not show any beneficial effects in reducing the severity of frequency of attacks (Gliddon et al., 2007). The increased phosphorylation of PTK is associated with the $\alpha_{2 C}$-AR-mediated vasoconstriction, thus PTK inhibitors may be used to reverse the contractile response to cooling, as these studies show that PTK phosphorylation is higher in RP patients arterioles in comparison to ctrl arterioles (Furspan et al., 2004, 2005). However, future studies must be done on this interesting type of treatment.

One of the early events thought to play a role in the vasculopathy of scleroderma is endothelial injury. Because such injury leads to increased release of the potent vasoconstrictor, endothlin-1, it was thought that blocking endothelin signaling and function could play a beneficial role in the treatment of systemic scleroderma (SSc) and the associated secondary RP. When ETRAs were employed, not all patients responded positively; nonetheless, these antagonists were able to at least alleviate the severity and frequency of vasospastic attacks (Poredos and Poredos, 2016). Several studies have looked at the effect of ETRAs in the treatment of SSc-associated RP. In 2006, the first prospective study investigating the potential benefit of ETRAs in RP was published (Selenko-Gebauer et al., 2006). The patients involved in this study received bosentan for 16-week, after which it was found that severity of RP attacks was significantly reduced. Another observational study also reported that after a median of 8 weeks of treatment with bosentan, severity of RP was also reduced (Funauchi et al., 2009). Whether beta blockers have a therapeutic value remains controversial. One studies involving 102 patients report that the beta blockers Propranolol, Oxprenolol, and Atenolol disturb the microcirculation causing RP as a side effect (Marshall et al., 1976). Consistent with this, a meta-analysis of 13 studies suggests that the use of beta blockers is associated with higher incidence of RP (Mohokum et al., 2012). On the other hand, other reports suggest that beta blockers could be beneficial particularly because of their ability to reduce blood viscosity (Koltringer et al., 1991). In this study, half of the 40 participants involved received metoprolol, and showed reduced blood viscosity compared to the control group. Interestingly, a combination treatment of beta blockers (metoprolol) with calcium channel inhibitors (felodipin) was shown to be very effective in reducing symptoms of RP (Csiki et al., 2011).

There are other drugs that appear to have a potential for use in the management of RP. These include statins (Abou-Raya et al., 2008) and serotonin receptor antagonists (Coleiro et al., 2001). Although their mechanism of action is not fully clear, they 
appear to retard vascular injury, lessen severity, and reduce pain associated with RP.

A recent report discussed the potential benefit of using a rather non-traditional approach for the treatment of RP. Botulinum toxin type A (BTX-A) can be locally injected to improve ulcerated digits and alleviate the associated pain (Neumeister et al., 2014). This improvement may be due to better perfusion and improved vascularity; however, the exact mechanism remains unknown. Notably, studies have shown that the use of BTX-A could be safe and efficient (Neumeister et al., 2014). In a recent retrospective study, it was shown that local injection of BTXA provides great improvement in artery flow velocity, surface temperature, ulcer, and other clinical symptoms (as measured by visual analog scale; Zhang et al., 2015). Others have also reported similar beneficial effects of BTX-A in the management of RP (Smith et al., 2012; Zhao and Lian, 2015). However, despite all these interesting and promising results, a recent systemic review concludes that evidence to support the efficacy of BTX-A in the management of RP remains insufficient. As such, further research, particularly randomized controlled trials, is needed to better determine the potential efficacy of this interesting approach.

It is worth mentioning that in some patients, the aforementioned pharmacological drugs may cause several side effects such as headaches and dizziness. As such, many patients resort to alternative therapies in the hope of avoiding such undesired side effects. Herbal therapies are one common approach. Of particular interest in the management of RP is Ginkgo biloba plant extracts (Muir et al., 2002) or a combination of two Chinese herbal medications, Duhuo-Tisheng Tang and Danggui-Sini Tang (Wu et al., 2008). However, contradictory reports suggest that that digital vascular response of RP patients receiving this therapy was not changed in patients consuming the above herbal combination (Appiah et al., 1997; Hirschl et al., 2004; Wu et al., 2008). Acupuncture has also be employed in the management of RP. Indeed, a randomized controlled prospective study concluded that traditional Chinese acupuncture appears to be an effective approach in relieving symptoms, particularly attack frequency, of primary RP (Appiah et al., 1997). Others have also reported that auricular electroacupuncture could be helpful in reducing severity and frequency of RP attacks (Schlager et al., 2011). However, meta-analysis and systematic review of the literature does not conclusively support the use of acupuncture in the management of RP (Malenfant et al., 2009; Huisstede et al., 2011).

Laser therapy has also received some attention. A randomized placebo-controlled double-blind crossover study involving 48 patients shows that low level laser therapy could reduce frequency and severity of RP attacks (Hirschl et al., 2004). Findings of this study are consistent with those of another double-blind study that appeared in the same year (al-Awami et al., 2004). Highpeak power laser treatment has also been reported to reduce the frequency and severity of attacks in a patient suffering from Scleroderma and RP (St Surin-Lord and Obagi, 2011).

It is important to note that surgical therapies may be considered as an option of treatment (Landry, 2013). These therapies include thoracic sympathectomy, hand stripping, and nerve stimulation (Kaada, 1982; Balogh et al., 2002; Coveliers et al., 2011). Although invasive, these are considered to be successful in pain reduction and ulcer healing (Landry, 2013). Finally, fat grafting in the patient's hands is a new and rather unconventional surgical therapy for RP patients (Bank et al., 2014). This novel treatment originated from clinical improvements observed after fat grafting in hands suffering from burns and radiation dermatitis (Rigotti et al., 2007). When it was later "tested" on a group of RP patients, the results were encouraging and included alleviation of pain, decrease of ulcers, and decline in cold attacks (Bank et al., 2014). Although the mechanism by which fat grafting caused these effects is largely unclear, it is hypothesized that pathways involving neoangiogenesis and stem cells are likely implicated (Bank et al., 2014).

The variability of the treatments and their altered efficacies calls for urgent and concerted efforts to better understand the molecular mechanisms underlying the disease, as well as to develop more targeted and efficient drugs. These drugs may include blockers of $\alpha_{2-A R s}$ as well as inhibitors of PTKs and Rho kinase (Lambova and Muller-Ladner, 2009). Indeed, the first proof of concept for ameliorating RP attacks by blocking $\alpha_{2}$ ARs came from a study by Freedman et al. (1995). This paper showed that yohimbine, $\alpha_{2}$-AR antagonist, but not prazosin, $\alpha_{1}$-AR antagonist, can significantly attenuate vasospastic attacks of RP. More specifically, a double-blind, placebo-controlled, randomized crossover study investigated the efficacy of OPC28326 , a selective $\alpha$-AR antagonist with preferential binding to the $\alpha_{2} \mathrm{C}-\mathrm{AR}$ subtype, in recovery from cold-induced vasospasm in secondary RP patients. This study showed that OPC-28326 is able to improve digital blood flow after acute cold challenge in patients with RP secondary to scleroderma (Wise et al., 2004). Another phase II, randomized, double-blind, crossover, single-dose, placebo-controlled, study also tested the efficacy of ORM-12741, a potent $\alpha_{2 C}-A R$ antagonist. Interestingly, findings of this study were unexpected in that ORM-12741 prolonged, rather than shortened, the duration of the coldinduced constriction of digital arteries evident by delayed rewarming after a cold challenge (Herrick et al., 2014). The reasons for this rather unexpected result remain unclear and thus, further research is warranted to better understand the intriguing biology of $\alpha_{2} \mathrm{C}-\mathrm{AR}$ especially as it related to $\mathrm{RP}$ pathophysiology.

\section{CONCLUSION AND PERSPECTIVES}

Despite the exponentially growing research and biomedical advances, a definitive and curative treatment for RP still poses a real and elusive challenge. Although many aspects and factors contributing to this disease have been dissected, the molecular mechanisms underlying the onset and progression of RP still require further investigations. This is, in no small part, due to the multifactorial etiology (hormonal, neuronal, and endothelial) of the disease. Another challenge is the absence of an appropriate animal model of the disease. The fact that $\alpha_{2} \mathrm{C}-\mathrm{AR}$ is expressed in many brain regions such as the olfactory bulb and the cerebral 
cortex further complicates the hunt for an RP-specific drug. This is especially challenging because $\alpha_{2 C}$-ARs are also implicated in presynaptic regulation of the heart. Thus, targeting $\alpha_{2 \mathrm{C}}$-ARs in an attempt to treat RP would not be most suitable, since it will affect the heart and brain as well. However, it is tempting to speculate that applying topical creams containing $\alpha_{2} \mathrm{C}$-ARs blockers to affected body parts could be beneficial, and likely with fewer side effects. However, rigorous basic research and clinical trials are needed to support this suggestion. So far, precaution is often effective in reducing cold-induced vasospastic attacks of RP.

\section{REFERENCES}

Abou-Raya, A., Abou-Raya, S., and Helmii, M. (2008). Statins: potentially useful in therapy of systemic sclerosis-related Raynaud's phenomenon and digital ulcers. J. Rheumatol. 35, 1801-1808.

Ahles, A., and Engelhardt, S. (2014). Polymorphic variants of adrenoceptors: pharmacology, physiology, and role in disease. Pharmacol. Rev. 66, 598-637. doi: $10.1124 /$ pr.113.008219

al-Awami, M., Schillinger, M., Maca, T., Pollanz, S., and Minar, E. (2004). Low level laser therapy for treatment of primary and secondary Raynaud's phenomenon. Vasa 33, 25-29. doi: 10.1024/0301-1526.33.1.25

Anderson, J. E., Held, N., and Wright, K. (2004). Raynaud's phenomenon of the nipple: a treatable cause of painful breastfeeding. Pediatrics 113, e360-e364. doi: 10.1542/peds.113.4.e360

Appiah, R., Hiller, S., Caspary, L., Alexander, K., and Creutzig, A. (1997). Treatment of primary Raynaud's syndrome with traditional Chinese acupuncture. J. Intern. Med. 241, 119-124. doi: 10.1046/j.13652796.1997.91105000.x

Bailey, S. R., Eid, A. H., Mitra, S., Flavahan, S., and Flavahan, N. A. (2004). Rho kinase mediates cold-induced constriction of cutaneous arteries: role of alpha2C-adrenoceptor translocation. Circ. Res. 94, 1367-1374. doi: 10.1161/01.RES.0000128407.45014.58

Bailey, S. R., Mitra, S., Flavahan, S., and Flavahan, N. A. (2005). Reactive oxygen species from smooth muscle mitochondria initiate cold-induced constriction of cutaneous arteries. Am. J. Physiol. Heart Circ. Physiol. 289, H243-H250. doi: 10.1152/ajpheart.01305.2004

Balogh, B., Mayer, W., Vesely, M., Mayer, S., Partsch, H., and Piza-Katzer, H. (2002). Adventitial stripping of the radial and ulnar arteries in Raynaud's disease. J. Hand Surg Am 27, 1073-1080. doi: 10.1053/jhsu.2002.35887

Bank, J., Fuller, S. M., Henry, G. I., and Zachary, L. S. (2014). Fat grafting to the hand in patients with Raynaud phenomenon: a novel therapeutic modality. Plast Reconstr. Surg. 133, 1109-1118. doi: 10.1097/PRS.0000000000000104

Belch, J. J. F., and Ho, M. (2001). "Vasospastic disorders and vasculitis," in Vascular and Endovascular Surgery, eds J. D. Beard and P. A. Gaines (London: WB Saunders and Company), 217-240.

Black, C. M. (1995). Systemic sclerosis 'state of the art' 1995. Scand. J. Rheumatol. 24, 194-196. doi: 10.3109/03009749509100872

Block, J. A., and Sequeira, W. (2001). Raynaud's phenomenon. Lancet 357, 2042-2048. doi: 10.1016/S0140-6736(00)05118-7

Caglayan, E., Huntgeburth, M., Karasch, T., Weihrauch, J., Hunzelmann, N., Krieg, T., et al. (2006). Phosphodiesterase type 5 inhibition is a novel therapeutic option in Raynaud disease. Arch. Intern. Med. 166, 231-233. doi: 10.1001/archinte.166.2.231

Cardelli, M. B., and Kleinsmith, D. M. (1989). Raynaud's phenomenon and disease. Med. Clin. North Am. 73, 1127-1141. doi: 10.1016/S0025-7125(16)30623-X

Carmichael, J. (1998). The role of gemcitabine in the treatment of other tumours. Br. J. Cancer 78(Suppl. 3), 21-25. doi: 10.1038/bjc.1998.750

Chan, N. N., MacAllister, R. J., Colhoun, H. M., Vallance, P., and Hingorani, A. D. (2001). Changes in endothelium-dependent vasodilatation and alphaadrenergic responses in resistance vessels during the menstrual cycle in healthy women. J. Clin. Endocrinol. Metab. 86, 2499-2504. doi: 10.1210/jcem.86.6. 7581

Chant, A. D. (1987). Exaggerated postural vasoconstrictor reflex in Raynaud's phenomenon. Br. Med. J. (Clin. Res. Ed.) 295:51. doi: 10.1136/bmj.295.6589.51-a

\section{AUTHOR CONTRIBUTIONS}

All authors contributed to the writing. AHE conceived, designed, and revised the manuscript.

\section{ACKNOWLEDGMENT}

The authors would like to thank Ms. Tuqa Saleh Al-Shehabi for her assistance in drawing the figures.

Charkoudian, N. (2010). Mechanisms and modifiers of reflex induced cutaneous vasodilation and vasoconstriction in humans. J. Appl. Physiol. (1985) 109, 1221-1228. doi: 10.1152/japplphysiol.00298.2010

Charkoudian, N., and Stachenfeld, N. (2016). Sex hormone effects on autonomic mechanisms of thermoregulation in humans. Auton. Neurosci. 196, 75-80. doi: 10.1016/j.autneu.2015.11.004

Cherniack, M., Clive, J., and Seidner, A. (2000). Vibration exposure, smoking, and vascular dysfunction. Occup. Environ. Med. 57, 341-347. doi: 10.1136/oem.57.5.341

Chitaley, K., and Webb, R. C. (2002). Microtubule depolymerization facilitates contraction of rat aorta via activation of Rho-kinase. Vascul. Pharmacol. 38, 157-161. doi: 10.1016/S1537-1891(02)00163-5

Chotani, M. A., Flavahan, S., Mitra, S., Daunt, D., and Flavahan, N. A. (2000). Silent alpha(2C)-adrenergic receptors enable cold-induced vasoconstriction in cutaneous arteries. Am. J. Physiol. Heart Circ. Physiol. 278, H1075-H1083.

Chotani, M. A., Mitra, S., Su, B. Y., Flavahan, S., Eid, A. H., Clark, K. R., et al. (2004). Regulation of alpha(2)-adrenoceptors in human vascular smooth muscle cells. Am. J. Physiol. Heart Circ. Physiol. 286, H59-H67. doi: 10.1152/ajpheart.00268.2003

Clifford, P. C., Martin, M. F., Sheddon, E. J., Kirby, J. D., Baird, R. N., and Dieppe, P. A. (1980). Treatment of vasospastic disease with prostaglandin E1. Br. Med. J. 281, 1031-1034. doi: 10.1136/bmj.281.6247.1031

Clowse, M. E., and Wigley, F. M. (2003). Digital necrosis related to carboplatin and gemcitabine therapy in systemic sclerosis. J. Rheumatol. 30, 1341-1343.

Coleiro, B., Marshall, S. E., Denton, C. P., Howell, K., Blann, A., Welsh, K. I., et al. (2001). Treatment of Raynaud's phenomenon with the selective serotonin reuptake inhibitor fluoxetine. Rheumatology (Oxford) 40, 1038-1043. doi: 10.1093/rheumatology/40.9.1038

Coveliers, H. M., Hoexum, F., Nederhoed, J. H., Wisselink, W., and Rauwerda, J. A. (2011). Thoracic sympathectomy for digital ischemia: a summary of evidence. J. Vasc. Surg. 54, 273-277. doi: 10.1016/j.jvs.2011.01.069

Coward, J., Maisey, N., and Cunningham, D. (2005). The effects of capecitabine in Raynaud's disease: a case report. Ann. Oncol. 16, 835-836. doi: 10.1093/annonc/mdi144

Csiki, Z., Garai, I., Shemirani, A. H., Papp, G., Zsori, K. S., Andras, C., et al. (2011). The effect of metoprolol alone and combined metoprolol-felodipin on the digital microcirculation of patients with primary Raynaud's syndrome. Microvasc. Res. 82, 84-87. doi: 10.1016/j.mvr.2011.04.004

D’Alessandro, V., Errico, M., Varriale, A., Greco, A., De Cata, A., Carnevale, V., et al. (2003). [Case report: Acro-necrosis of the upper limbs caused by gemcitabine therapy]. Clin. Ter. 154, 207-210.

Dziadzio, M., Denton, C. P., Smith, R., Howell, K., Blann, A., Bowers, E., et al. (1999). Losartan therapy for Raynaud's phenomenon and scleroderma: clinical and biochemical findings in a fifteen-week, randomized, parallelgroup, controlled trial. Arthritis Rheum. 42, 2646-2655. doi: 10.1002/15290131(199912)42:12<2646::AID-ANR21>3.0.CO;2-T

Easter, M. J., and Marshall, J. M. (2005). Contribution of prostanoids to endothelium-dependent vasodilatation in the digital circulation of women with primary Raynaud's disease. Clin. Sci. (Lond). 109, 45-54. doi: 10.1042/CS20040262

Eid, A. H., Chotani, M. A., Mitra, S., Miller, T. J., and Flavahan, N. A. (2008). Cyclic AMP acts through Rap1 and JNK signaling to increase expression of cutaneous smooth muscle alpha2C-adrenoceptors. Am. J. Physiol. Heart Circ. Physiol. 295, H266-H272. doi: 10.1152/ajpheart.00084.2008 
Eid, A. H., Maiti, K., Mitra, S., Chotani, M. A., Flavahan, S., Bailey, S. R., et al. (2007). Estrogen increases smooth muscle expression of alpha2C-adrenoceptors and cold-induced constriction of cutaneous arteries. Am. J. Physiol. Heart Circ. Physiol. 293, H1955-H1961. doi: 10.1152/ajpheart.00306.2007

English, K. M., Jones, R. D., Jones, T. H., Morice, A. H., and Channer, K. S. (2001). Gender differences in the vasomotor effects of different steroid hormones in rat pulmonary and coronary arteries. Horm. Metab. Res. 33, 645-652. doi: 10.1055/s-2001-18689

Ennis, H., Hughes, M., Anderson, M. E., Wilkinson, J., and Herrick, A. L. (2016). Calcium channel blockers for primary Raynaud's phenomenon. Cochrane Database Syst. Rev. 2: CD002069. doi: 10.1002/14651858.CD002069. pub5

Falappa, P., Magnavita, N., Bergamaschi, A., and Colavita, N. (1982). Angiographic study of digital arteries in workers exposed to vinyl chloride. $\mathrm{Br}$. J. Ind. Med. 39, $169-172$.

Flavahan, N. A. (2015). A vascular mechanistic approach to understanding Raynaud phenomenon. Nat. Rev. Rheumatol. 11, 146-158. doi: 10.1038/nrrheum.2014.195

Fletcher, D. A., and Mullins, R. D. (2010). Cell mechanics and the cytoskeleton. Nature 463, 485-492. doi: 10.1038/nature08908

Fontana, L., Marion, M. J., Ughetto, S., and Catilina, P. (2006). Glutathione S-transferase M1 and GST T1 genetic polymorphisms and Raynaud's phenomenon in French vinyl chloride monomer-exposed workers. J. Hum. Genet. 51, 879-886. doi: 10.1007/s10038-006-0038-9

Fraenkel, L., Zhang, Y., Chaisson, C. E., Evans, S. R., Wilson, P. W., and Felson, D. T. (1998). The association of estrogen replacement therapy and the Raynaud phenomenon in postmenopausal women. Ann. Intern. Med. 129, 208-211. doi: 10.7326/0003-4819-129-3-199808010-00009

Freedman, R. R., Baer, R. P., and Mayes, M. D. (1995). Blockade of vasospastic attacks by alpha 2-adrenergic but not alpha 1-adrenergic antagonists in idiopathic Raynaud's disease. Circulation 92, 1448-1451. doi: 10.1161/01.CIR.92.6.1448

Freedman, R. R., Moten, M., Migaly, P., and Mayes, M. (1993). Cold-induced potentiation of alpha 2-adrenergic vasoconstriction in primary Raynaud's disease. Arthritis Rheum. 36, 685-690. doi: 10.1002/art.1780360517

Freedman, R. R., Sabharwal, S. C., Moten, M., and Migaly, P. (1992). Local temperature modulates alpha 1- and alpha 2-adrenergic vasoconstriction in men. Am. J. Physiol. 263, H1197-H1200.

Funauchi, M., Kishimoto, K., Shimazu, H., Nagare, Y., Hino, S., Yano, T., et al. (2009). Effects of bosentan on the skin lesions: an observational study from a single center in Japan. Rheumatol. Int. 29, 769-775. doi: 10.1007/s00296-0080789-z

Furspan, P. B., Chatterjee, S., and Freedman, R. R. (2004). Increased tyrosine phosphorylation mediates the cooling-induced contraction and increased vascular reactivity of Raynaud's disease. Arthritis Rheum. 50, 1578-1585. doi: 10.1002/art.20214

Furspan, P. B., Chatterjee, S., Mayes, M. D., and Freedman, R. R. (2005). Cooling-induced contraction and protein tyrosine kinase activity of isolated arterioles in secondary Raynaud's phenomenon. Rheumatology 44, 488-494. doi: 10.1093/rheumatology/keh517

Garner, R., Kumari, R., Lanyon, P., Doherty, M., and Zhang, W. (2015). Prevalence, risk factors and associations of primary Raynaud's phenomenon: systematic review and meta-analysis of observational studies. BMJ Open 5: e006389. doi: 10.1136/bmjopen-2014-006389

Gentric, A., Blaschek, M. A., Le Noach, J. F., Johanet, C., Jouquan, J., Lamour, A., et al. (1990). Serological arguments for classifying Raynaud's phenomenon as idiopathic. J. Rheumatol. 17, 1177-1181.

Gerbracht, D. D., Steen, V. D., Ziegler, G. L., Medsger, T. A. Jr., and Rodnan, G. P. (1985). Evolution of primary Raynaud's phenomenon (Raynaud's disease) to connective tissue disease. Arthritis Rheum. 28, 87-92. doi: 10.1002/art.1780280114

Glendenning, J. L., Barbachano, Y., Norman, A. R., Dearnaley, D. P., Horwich, A., and Huddart, R. A. (2010). Long-term neurologic and peripheral vascular toxicity after chemotherapy treatment of testicular cancer. Cancer 116, 2322-2331. doi: 10.1002/cncr.24981

Gliddon, A. E., Dore, C. J., Black, C. M., McHugh, N., Moots, R., Denton, C. P., et al. (2007). Prevention of vascular damage in scleroderma and autoimmune
Raynaud's phenomenon: a multicenter, randomized, double-blind, placebocontrolled trial of the angiotensin-converting enzyme inhibitor quinapril. Arthritis Rheum. 56, 3837-3846. doi: 10.1002/art.22965

Gottschling, S., Meyer, S., Reinhard, H., Krenn, T., and Graf, N. (2004). First report of a vincristine dose-related Raynaud's phenomenon in an adolescent with malignant brain tumor. J. Pediatr. Hematol. Oncol. 26, 768-769. doi: 10.1097/00043426-200411000-00017

Greenstein, D., Jeffcote, N., Ilsley, D., and Kester, R. C. (1996). The menstrual cycle and Raynaud's phenomenon. Angiology 47, 427-436. doi: $10.1177 / 000331979604700501$

Guimaraes, S., and Moura, D. (2001). Vascular adrenoceptors: an update. Pharmacol. Rev. 53, 319-356.

Halawa, B. (2001). [Calcium channel blockers in the treatment of cardiovascular disease]. Pol. Merkur. Lekarski 11, 83-87.

Hall, A. (1998). Rho GTPases and the actin cytoskeleton. Science 279, 509-514. doi: $10.1126 /$ science. 279.5350 .509

Hall, A. H. (2002). Chronic arsenic poisoning. Toxicol. Lett. 128, 69-72. doi: 10.1016/S0378-4274(01)00534-3

Hansen, S. W., and Olsen, N. (1989). Raynaud's phenomenon in patients treated with cisplatin, vinblastine, and bleomycin for germ cell cancer: measurement of vasoconstrictor response to cold. J. Clin. Oncol. 7, 940-942.

Heidrich, H. (2010). Functional vascular diseases: Raynaud's syndrome, acrocyanosis and erythromelalgia. Vasa 39, 33-41. doi: 10.1024/0301$1526 / \mathrm{a} 000003$

Henness, S., and Wigley, F. M. (2007). Current drug therapy for scleroderma and secondary Raynaud's phenomenon: evidence-based review. Curr. Opin. Rheumatol. 19, 611-618. doi: 10.1097/BOR.0b013e3282f13137

Herrick, A. L. (2012). The pathogenesis, diagnosis and treatment of Raynaud phenomenon. Nat. Rev. Rheumatol. 8, 469-479. doi: 10.1038/nrrheum.2012.96

Herrick, A. L., Murray, A. K., Ruck, A., Rouru, J., Moore, T. L., Whiteside, J., et al. (2014). A double-blind, randomized, placebo-controlled crossover trial of the alpha2C-adrenoceptor antagonist ORM-12741 for prevention of coldinduced vasospasm in patients with systemic sclerosis. Rheumatology (Oxford) 53, 948-952. doi: 10.1093/rheumatology/ket421

Hirschl, M., Katzenschlager, R., Francesconi, C., and Kundi, M. (2004). Low level laser therapy in primary Raynaud's phenomenon-results of a placebo controlled, double blind intervention study. J. Rheumatol. 31, 2408-2412.

Holstein, A., Batge, R., and Egberts, E. H. (2010). Gemcitabine induced digital ischaemia and necrosis. Eur. J. Cancer Care (Engl). 19, 408-409. doi: 10.1111/j.1365-2354.2008.01057.x

Huisstede, B. M., Hoogvliet, P., Paulis, W. D., van Middelkoop, M., Hausman, M., Coert, J. H., et al. (2011). Effectiveness of interventions for secondary Raynaud's phenomenon: a systematic review. Arch. Phys. Med. Rehabil. 92, 1166-1180. doi: 10.1016/j.apmr.2011.01.022

Hurt, C. M., Feng, F. Y., and Kobilka, B. (2000). Cell-type specific targeting of the alpha 2c-adrenoceptor. Evidence for the organization of receptor microdomains during neuronal differentiation of PC12 cells. J. Biol. Chem. 275, 35424-35431. doi: 10.1074/jbc.M006241200

Jackson, C. M. (2006). The patient with cold hands: understanding Raynaud's disease. JAAPA 19, 34-38.

Janini, S. D., Scott, D. G., Coppock, J. S., Bacon, P. A., and Kendall, M. J. (1988). Enalapril in Raynaud's phenomenon. J. Clin. Pharm. Ther. 13, 145-150. doi: 10.1111/j.1365-2710.1988.tb00171.x

Jeyaraj, S. C., Chotani, M. A., Mitra, S., Gregg, H. E., Flavahan, N. A., and Morrison, K. J. (2001). Cooling evokes redistribution of alpha2C-adrenoceptors from Golgi to plasma membrane in transfected human embryonic kidney 293 cells. Mol. Pharmacol. 60, 1195-1200.

Jeyaraj, S. C., Unger, N. T., Eid, A. H., Mitra, S., Paul El-Dahdah, N., Quilliam, L. A., et al. (2012). Cyclic AMP-Rap1A signaling activates RhoA to induce alpha(2c)-adrenoceptor translocation to the cell surface of microvascular smooth muscle cells. Am. J. Physiol. Cell Physiol. 303, C499-C511. doi: 10.1152/ajpcell.00461.2011

Johnson, J. M., and Kellogg, D. L. Jr. (2010). Local thermal control of the human cutaneous circulation. J. Appl. Physiol. (1985) 109, 1229-1238. doi: 10.1152/japplphysiol.00407.2010

Kaada, B. (1982). Vasodilation induced by transcutaneous nerve stimulation in peripheral ischemia (Raynaud's phenomenon and diabetic polyneuropathy). Eur. Heart J. 3, 303-314. 
Kawald, A., Burmester, G. R., Huscher, D., Sunderkotter, C., and Riemekasten, G. (2008). Low versus high-dose iloprost therapy over 21 days in patients with secondary Raynaud's phenomenon and systemic sclerosis: a randomized, open, single-center study. J. Rheumatol. 35, 1830-1837.

Koltringer, P., Langsteger, W., Pierer, G., Lind, P., Klima, G., Reisecker, F., et al. (1991). [Effect of metoprolol on microcirculation and blood viscoelasticity]. Acta Med. Austriaca 18, 75-77.

Kristensen, J. K. (1979). Local regulation of digital blood flow in generalized scleroderma. J. Invest. Dermatol. 72, 235-240. doi: 10.1111/1523-1747.ep12531698

Kuhar, C. G., Mesti, T., and Zakotnik, B. (2010). Digital ischemic events related to gemcitabine: report of two cases and a systematic review. Radiol. Oncol. 44, 257-261. doi: 10.2478/v10019-010-0020-1

Kundu, D., Abraham, D., Black, C. M., Denton, C. P., and Bruckdorfer, K. R. (2014). Reduced levels of S-nitrosothiols in plasma of patients with systemic sclerosis and Raynaud's phenomenon. Vascul. Pharmacol. 63, 178-181. doi: 10.1016/j.vph.2014.09.003

Lagerkvist, B., Linderholm, H., and Nordberg, G. F. (1986). Vasospastic tendency and Raynaud's phenomenon in smelter workers exposed to arsenic. Environ. Res. 39, 465-474. doi: 10.1016/S0013-9351(86)80070-6

Lambova, S. N., and Muller-Ladner, U. (2009). New lines in therapy of Raynaud's phenomenon. Rheumatol. Int. 29, 355-363. doi: 10.1007/s00296-008-0792-4

Landry, G. J. (2013). Current medical and surgical management of Raynaud's syndrome. J. Vasc. Surg. 57, 1710-1716. doi: 10.1016/j.jvs.2013.03.012

Le Quentrec, P., and Lefebvre, M. L. (1991). Double-blind placebo-controlled trial of buflomedil in the treatment of Raynaud's phenomenon: six-month follow-up. Angiology 42, 289-295. doi: 10.1177/000331979104200405

Lee, E. Y., Park, J. K., Lee, W., Kim, Y. K., Park, C. S., Giles, J. T., et al. (2014). Head-to-head comparison of udenafil vs amlodipine in the treatment of secondary Raynaud's phenomenon: a double-blind, randomized, cross-over study. Rheumatology (Oxford) 53, 658-664. doi: 10.1093/rheumatology/ket417

Leppert, J., Aberg, H., Levin, K., and Ringqvist, I. (1990). Lower serum magnesium level after exposure to cold in women with primary Raynaud's phenomenon. J. Intern. Med. 228, 235-239. doi: 10.1111/j.1365-2796.1990.tb00224.x

Li, T., Xiao, X., Zhang, J., Zhu, Y., Hu, Y., Zang, J., et al. (2014). Age and sex differences in vascular responsiveness in healthy and trauma patients: contribution of estrogen receptor-mediated Rho kinase and PKC pathways. Am. J. Physiol. Heart Circ. Physiol. 306, H1105-H1115. doi: 10.1152/ajpheart.00645.2013

Linnemann, B., and Erbe, M. (2016). Raynaud's phenomenon and digital ischaemia-pharmacologic approach and alternative treatment options. Vasa 45, 201-212. doi: 10.1024/0301-1526/a000526

MacDonald, E., Kobilka, B. K., and Scheinin, M. (1997). Gene targeting-homing in on alpha 2-adrenoceptor-subtype function. Trends Pharmacol. Sci. 18, 211-219. doi: 10.1016/S0165-6147(97)01063-8

Malenfant, D., Catton, M., and Pope, J. E. (2009). The efficacy of complementary and alternative medicine in the treatment of Raynaud's phenomenon: a literature review and meta-analysis. Rheumatology (Oxford) 48, 791-795. doi: 10.1093/rheumatology/kep039

Maricq, H. R., Carpentier, P. H., Weinrich, M. C., Keil, J. E., Franco, A., Drouet, P., et al. (1993). Geographic variation in the prevalence of Raynaud's phenomenon: Charleston, SC, USA, vs Tarentaise, Savoie, France. J. Rheumatol. 20, 70-76.

Maricq, H. R., Darke, C. S., Archibald, R. M., and Leroy, E. C. (1978). In vivo observations of skin capillaries in workers exposed to vinyl chloride. An English-American comparison. Br. J. Ind. Med. 35, 1-7.

Maricq, H. R., Johnson, M. N., Whetstone, C. L., and LeRoy, E. C. (1976). Capillary abnormalities in polyvinyl chloride production workers. Examination by in vivo microscopy. JAMA 236, 1368-1371. doi: 10.1001/jama.236.12.1368

Marshall, A. J., Roberts, C. J., and Barritt, D. W. (1976). Raynaud's phenomenon as side effect of beta-blockers in hypertension. Br. Med. J. 1, 1498-1499. doi: 10.1136/bmj.1.6024.1498

Maverakis, E., Patel, F., Kronenberg, D. G., Chung, L., Fiorentino, D., Allanore, Y., et al. (2014). International consensus criteria for the diagnosis of Raynaud's phenomenon. J. Autoimmun. 4, 60-65. doi: 10.1016/j.jaut.2014.01.020

Mayes, M. D. (1999). Epidemiologic studies of environmental agents and systemic autoimmune diseases. Environ. Health Perspect. 107(Suppl. 5), 743-748. doi: $10.2307 / 3434336$
McCance, K. L., and Huether, S. E. (2013). Pathophysiology: The Biologic Basis for Disease in Adults and Children. Amsterdam: Elsevier.

McNeill, A. M., Leslie, F. M., Krause, D. N., and Duckles, S. P. (1999). Gender difference in levels of alpha2-adrenoceptor mRNA in the rat tail artery. Eur. J. Pharmacol. 366, 233-236. doi: 10.1016/S0014-2999(98)00948-0

Milio, G., Corrado, E., Genova, C., Amato, C., Raimondi, F., Almasio, P. L., et al. (2006). Iloprost treatment in patients with Raynaud's phenomenon secondary to systemic sclerosis and the quality of life: a new therapeutic protocol. Rheumatology (Oxford) 45, 999-1004. doi: 10.1093/rheumatology/kel038

Mohokum, M., Hartmann, P., and Schlattmann, P. (2012). The association of Raynaud syndrome with beta-blockers: a meta-analysis. Angiology 63, 535-540. doi: 10.1177/0003319711432861

Mohrland, J. S., Porter, J. M., Smith, E. A., Belch, J., and Simms, M. H. (1985). A multiclinic, placebo-controlled, double-blind study of prostaglandin E1 in Raynaud's syndrome. Ann. Rheum. Dis. 44, 754-760. doi: 10.1136/ard.44. 11.754

Motawea, H. K., Jeyaraj, S. C., Eid, A. H., Mitra, S., Unger, N. T., Ahmed, A. A., et al. (2013). Cyclic AMP-Rap1A signaling mediates cell surface translocation of microvascular smooth muscle alpha2C-adrenoceptors through the actinbinding protein filamin-2. Am. J. Physiol. Cell Physiol. 305, C829-C845. doi: 10.1152/ajpcell.00221.2012

Muir, A. H., Robb, R., McLaren, M., Daly, F., and Belch, J. J. (2002). The use of Ginkgo biloba in Raynaud's disease: a double-blind placebo-controlled trial. Vasc. Med. 7, 265-267. doi: 10.1191/1358863x02vm455oa

Neumeister, M. W., Webb, K. N., and Romanelli, M. (2014). Minimally invasive treatment of Raynaud phenomenon: the role of botulinum type A. Hand Clin. 30, 17-24. doi: 10.1016/j.hcl.2013.09.006

Nordberg, G. F., Fowler, B. A., Nordberg, M., and Friberg, L. (2014). Handbook on the Toxicology of Metals. Amsterdam: Academic Press.

Nyronen, T., Pihlavisto, M., Peltonen, J. M., Hoffren, A. M., Varis, M., Salminen, T., et al. (2001). Molecular mechanism for agonist-promoted alpha(2A)-adrenoceptor activation by norepinephrine and epinephrine. Mol. Pharmacol. 59, 1343-1354.

Olsen, N., Petring, O. U., and Rossing, N. (1987). Exaggerated postural vasoconstrictor reflex in Raynaud's phenomenon. Br. Med. J. (Clin. Res. Ed.) 294, 1186-1188. doi: 10.1136/bmj.294.6581.1186

Pawlowski, M., Saraswathi, S., Motawea, H. K., Chotani, M. A., and Kloczkowski, A. (2014). In silico modeling of human alpha2Cadrenoreceptor interaction with filamin-2. PLOS ONE 9:e103099. doi: 10.1371/journal.pone.0103099

Pistorius, M. A., Planchon, B., Schott, J. J., and Lemarec, H. (2006). [Heredity and genetic aspects of Raynaud's disease]. J. Mal. Vasc. 31, 10-15. doi: 10.1016/S0398-0499(06)76512-X

Polonia, J. J., Paiva, M. Q., and Guimaraes, S. (1985). Pharmacological characterization of postsynaptic alpha-adrenoceptor subtypes in five different dog arteries in-vitro. J. Pharm. Pharmacol. 37, 205-208. doi: 10.1111/j.20427158.1985.tb05043.x

Pope, J., Fenlon, D., Thompson, A., Shea, B., Furst, D., Wells, G., et al. (2000). Iloprost and cisaprost for Raynaud's phenomenon in progressive systemic sclerosis. Cochrane Database Syst. Rev. 2:CD000953. doi: 10.1002/14651858.CD000953

Poredos, P., and Poredos, P. (2016). Raynaud's syndrome: a neglected disease. Int. Angiol. 35, 117-121.

Prete, M., Fatone, M. C., Favoino, E., and Perosa, F. (2014). Raynaud's phenomenon: from molecular pathogenesis to therapy. Autoimmun. Rev. 13, 655-667. doi: 10.1016/j.autrev.2013.12.001

Rademaker, M., Thomas, R. H., Provost, G., Beacham, J. A., Cooke, E. D., and Kirby, J. D. (1987). Prolonged increase in digital blood flow following iloprost infusion in patients with systemic sclerosis. Postgrad. Med. J. 63, 617-620. doi: 10.1136/pgmj.63.742.617

Reslan, O. M., and Khalil, R. A. (2012). Vascular effects of estrogenic menopausal hormone therapy. Rev. Recent Clin. Trials 7, 47-70. doi: $10.2174 / 157488712799363253$

Rigotti, G., Marchi, A., Galie, M., Baroni, G., Benati, D., Krampera, M., et al. (2007). Clinical treatment of radiotherapy tissue damage by lipoaspirate transplant: a healing process mediated by adipose-derived adult stem cells. Plast Reconstr. Surg. 119, 1409-1422; discussion1423-1404. doi: 10.1097/01.prs.0000256047.47909.71 
Roustit, M., Khouri, C., Blaise, S., Villier, C., Carpentier, P., and Cracowski, J. L. (2014). [Pharmacology of Raynaud's phenomenon]. Therapie 69, 115-128. doi: $10.2515 /$ therapie/2013068

Rychlik-Golema, W., Mastej, K., and Adamiec, R. (2006). The role of endothelin-1 and selected cytokines in the pathogenesis of Raynaud's phenomenon associated with systemic connective tissue diseases. Int. Angiol. 25, 221-227.

Saif, M. W., Agarwal, A., Hellinger, J., Park, D. J., and Volkmann, E. (2016). Scleroderma in a patient on capecitabine: is this a variant of hand-foot syndrome? Cureus 8:e663. doi: 10.7759/cureus.663

Sallinen, J., Link, R. E., Haapalinna, A., Viitamaa, T., Kulatunga, M., Sjoholm, B., et al. (1997). Genetic alteration of alpha 2C-adrenoceptor expression in mice: influence on locomotor, hypothermic, and neurochemical effects of dexmedetomidine, a subtype-nonselective alpha 2-adrenoceptor agonist. Mol. Pharmacol. 51, 36-46.

Schlager, O., Gschwandtner, M. E., Mlekusch, I., Herberg, K., Frohner, T., Schillinger, M., et al. (2011). Auricular electroacupuncture reduces frequency and severity of Raynaud attacks. Wien. Klin. Wochenschr. 123, 112-116. doi: 10.1007/S00508-011-1531-5

Scorza, R., Caronni, M., Mascagni, B., Berruti, V., Bazzi, S., Micallef, E., et al. (2001). Effects of long-term cyclic iloprost therapy in systemic sclerosis with Raynaud's phenomenon. A randomized, controlled study. Clin. Exp. Rheumatol. 19, 503-508.

Selenko-Gebauer, N., Duschek, N., Minimair, G., Stingl, G., and Karlhofer, F. (2006). Successful treatment of patients with severe secondary Raynaud's phenomenon with the endothelin receptor antagonist bosentan. Rheumatology (Oxford) 45(Suppl. 3), iii45-iii48. doi: 10.1093/rheumatology/kel290

Sharathkumar, A. A., and Castillo-Caro, P. (2011). Primary Raynaud's phenomenon in an infant: a case report and review of literature. Pediatr. Rheumatol. Online J. 9:16. doi: 10.1186/1546-0096-9-16

Smith, L., Polsky, D., and Franks, A. G. Jr. (2012). Botulinum toxin-A for the treatment of Raynaud syndrome. Arch. Dermatol. 148, 426-428. doi: 10.1001/archdermatol.2011.1144

Spengler, M. I., Svetaz, M. J., Leroux, M. B., Leiva, M. L., and Bottai, H. M. (2004). Association between capillaroscopy, haemorheological variables and plasma proteins in patients bearing Raynaud's phenomenon. Clin. Hemorheol. Microcirc. 30, 17-24.

St Surin-Lord, S., and Obagi, S. (2011). Scleroderma and raynaud's phenomenon improve with high-peak power laser therapy: a case report. Dermatol. Surg. 37, 1531-1535. doi: 10.1111/j.1524-4725.2011.02093.x

Stewart, M., and Morling, J. R. (2012). Oral vasodilators for primary Raynaud's phenomenon. Cochrane Database Syst. Rev. 7:CD006687. doi: 10.1002/14651858.CD006687.pub3

Susol, E., MacGregor, A. J., Barrett, J. H., Wilson, H., Black, C., Welsh, K., et al. (2000). A two-stage, genome-wide screen for susceptibility loci in primary Raynaud's phenomenon. Arthritis Rheum. 43, 1641-1646. doi: 10.1002/15290131(200007)43:7<1641::AID-ANR30>3.0.CO;2-Y

Tan, F. K., and Arnett, F. C. (2000). Genetic factors in the etiology of systemic sclerosis and Raynaud phenomenon. Curr. Opin. Rheumatol. 12, 511-519. doi: 10.1097/00002281-200011000-00007

Thompson, A. E., and Pope, J. E. (2005). Calcium channel blockers for primary Raynaud's phenomenon: a meta-analysis. Rheumatology (Oxford) 44, 145-150. doi: 10.1093/rheumatology/keh390

Tosi, S., Marchesoni, A., Messina, K., Bellintani, C., Sironi, G., and Faravelli, C. (1987). Treatment of Raynaud's phenomenon with captopril. Drugs Exp. Clin. Res. 13, 37-42.

Vanhoutte, P. M. (1980). "Physical factors and regulation of vascular smooth muscle function," in Handbook of Physiology, eds D. F. Bohr, A. P. Somlyo, and H. V. Sparks (Washington, DC: The American Physiological Society), 443-474.

Venat-Bouvet, L., Ly, K., Szelag, J. C., Martin, J., Labourey, J. L., Genet, D., et al. (2003). Thrombotic microangiopathy and digital necrosis: two unrecognized toxicities of gemcitabine. Anticancer. Drugs 14, 829-832. doi: 10.1097/01.cad.0000098998.92896.01
Vogelzang, N. J., Bosl, G. J., Johnson, K., and Kennedy, B. J. (1981). Raynaud's phenomenon: a common toxicity after combination chemotherapy for testicular cancer. Ann. Intern. Med. 95, 288-292. doi: 10.7326/0003-4819-953-288

von Zastrow, M., and Kobilka, B. K. (1994). Antagonist-dependent and independent steps in the mechanism of adrenergic receptor internalization. J. Biol. Chem. 269, 18448-18452.

White, C. R., Haidekker, M. A., Stevens, H. Y., and Frangos, J. A. (2004). Extracellular signal-regulated kinase activation and endothelin-1 production in human endothelial cells exposed to vibration. J. Physiol. 555, 565-572. doi: 10.1113/jphysiol.2003.059899

Wigley, F. M. (2002). Clinical practice. Raynaud's phenomenon. N. Engl. J. Med. 347, 1001-1008. doi: 10.1056/NEJMcp013013

Wigley, F. M., and Flavahan, N. A. (2016). Raynaud's phenomenon. N. Engl. J. Med. 375, 556-565. doi: 10.1056/NEJMra1507638

Wigley, F. M., Wise, R. A., Seibold, J. R., McCloskey, D. A., Kujala, G., Medsger, T. A., et al. (1994). Intravenous iloprost infusion in patients with Raynaud phenomenon secondary to systemic sclerosis. A multicenter, placebo-controlled, double-blind study. Ann. Intern. Med. 120, 199-206. doi: 10.7326/0003-4819-120-3-199402010-00004

William, N. R., and Markowitz, S. B. (2007). Environmental and Occupational Medicine. Philadelphia: Lippincott Williams \& Wilkins.

Wilson, R. H., McCormick, W. E., Tatum, C. F., and Creech, J. L. (1967). Occupational acroosteolysis. Report of 31 cases. JAMA 201, 577-581. doi: 10.1001/jama.1967.03130080019005

Wise, R. A., Wigley, F. M., White, B., Leatherman, G., Zhong, J., Krasa, H., et al. (2004). Efficacy and tolerability of a selective alpha(2C)-adrenergic receptor blocker in recovery from cold-induced vasospasm in scleroderma patients: a single-center, double-blind, placebo-controlled, randomized crossover study. Arthritis Rheum. 50, 3994-4001. doi: 10.1002/art.20665

Wood, H. M., and Ernst, M. E. (2006). Renin-angiotensin system mediators and Raynaud's phenomenon. Ann. Pharmacother. 40, 1998-2002. doi: 10.1345/aph.1H201

Wu, Y. J., Luo, S. F., Yang, S. H., Chen, J. Y., Yu, K. H., and See, L. C. (2008). Vascular response of Raynaud's phenomenon to nifedipine or herbal medication (duhuo-tisheng tang with danggui-sini tang): a preliminary study. Chang Gung Med. J. 31, 492-502.

Yamada, Y., Suzuki, K., Nobata, H., Kawai, H., Wakamatsu, R., Miura, N., et al. (2014). Gemcitabine-induced hemolytic uremic syndrome mimicking scleroderma renal crisis presenting with Raynaud's phenomenon, positive antinuclear antibodies and hypertensive emergency. Intern. Med. 53, 445-448. doi: 10.2169/internalmedicine.53.1160

Zamora, M. R., O'Brien, R. F., Rutherford, R. B., and Weil, J. V. (1990). Serum endothelin-1 concentrations and cold provocation in primary Raynaud's phenomenon. Lancet 336, 1144-1147. doi: 10.1016/0140-6736(90)92766-B

Zhang, X., Hu, Y., Nie, Z., Song, Y., Pan, Y., Liu, Y., et al. (2015). Treatment of Raynaud's phenomenon with botulinum toxin type A. Neurol. Sci. 36, 1225-1231. doi: 10.1007/s10072-015-2084-6

Zhao, H., and Lian, Y. (2015). Clinical and image improvement of Raynaud's phenomenon after botulinum toxin type A treatment. Australas. J. Dermatol. 56, 202-205. doi: 10.1111/ajd.12326

Conflict of Interest Statement: The authors declare that the research was conducted in the absence of any commercial or financial relationships that could be construed as a potential conflict of interest.

Copyright (C) 2016 Fardoun, Nassif, Issa, Baydoun and Eid. This is an open-access article distributed under the terms of the Creative Commons Attribution License (CC BY). The use, distribution or reproduction in other forums is permitted, provided the original author(s) or licensor are credited and that the original publication in this journal is cited, in accordance with accepted academic practice. No use, distribution or reproduction is permitted which does not comply with these terms. 